Lodovico Balducci, William Ershler, Giovanni de Gaetano (eds)

\section{Blood Disorders in the Elderly}

Cambridge University Press, Cambridge 2008

496 pp.; GBP 65.00/USD 130.00

ISBN 978-0-521-87573-8

This hardcover book is a multi-author treatise on blood disorders frequent in the senior population. This vast subject is covered on about 480 pages divided in 5 parts, each containing $4-11$ chapters, written by selected specialists.

Haematologic disorders, covering from mild to severe diseases, are part of everyday practice in geriatric wards. For this reason this book could be welcome on the shelves of geriatricians dealing with internal medicine. Most co-authors are either from the USA or from Italy. Balducci is Division Chief of the Senior Adult Oncology Program at the H. Lee Moffitt Cancer Centre in Tampa, Fla., USA, Ershler is Director of the Institute for Advanced Studies in Aging and Geriatric Medicine in Washington, D.C., and de Gaetano is Director of the Research Laboratories at the Centre for High Technology Research and Education in Biomedical Sciences at the Catholic University in Campobasso, Italy.

Part I of the book is on 'Epidemiology' with 4 chapters on: (1) Epidemiology of aging, (2) Epidemiology of anaemia in older adults, (3) Cancer in older persons: a comprehensive approach, and finally (4) From fitness to frailty: towards a nosologic classification of the older aged person.

Part II treats 'Hematopoiesis' in 7 chapters: (1) Stem cell exhaustion and aging, (2) Hematopoietic microenvironment and age, (3) Replicative senescence, aging and cancer, (4) Qualitative changes of hematopoiesis, (5) Aging and hematopoietic stress, (6) Immunoglobulin response and aging, and finally (7) Biological and clinical significance of monoclonal gammapathy.
Part III is on 'Anemia and Aging' with 6 chapters devoted to: (1) Erythropoietin and aging, (2) Iron and aging, (3) Prevalence and mechanisms of $\mathrm{B}_{12}$ deficiency, (4) Consequences of anemia in the older person, (5) The pathogenesis of late life anemia, and finally (6) Treatment of late life anemia.

Part IV is entitled 'Hematologic Malignancies and Aging' with 8 chapters as follows: (1) Cancer chemotherapy in the older person, (2) Acute myeloid leukaemia in the elderly, (3) Acute lymphoblastic leukaemia in the elderly patient: diagnosis and therapy, (4) Multiple myeloma, (5) Non-Hodgkin lymphoma, (6) Unusual lymphomas in the elderly, (7) Chronic lymphocytic leukaemia in the elderly, and finally (8) Polycythemia vera and idiopathic myelofibrosis in the elderly.

Part V contains 5 chapters: (1) Acquired haemophilia in the elderly, (2) Blood coagulation and aging, (3) Platelet disorders of the elderly, (4) Gene-environment interactions and vascular risk in the elderly, and finally (5) Antithrombotic therapy: guidelines for the elderly, followed by an Index.

A colour-plate section is inserted in the middle of the text, reproducing in colour the black and white figures of the text. Every chapter contains figures and tables as well as a long list of references. A final index facilitates the finding of topics of interest.

The subject of this book, if covered in detail, could fill an encyclopaedia. The authors managed to treat the above listed topics in a comprehensive manner, limiting thereby the volume of this treatise. The texts are written in an easily understandable style, mostly in correct English. The chapter headings listed show clearly that the chosen topic is well covered. For these reasons this book is highly recommended for geriatric clinical practitioners.

L. Robert, Paris
KARGER

(ㄷ) 2008 S. Karger AG, Basel

Fax +41 613061234 E-Mail karger@karger.ch www.karger.com www.karger.com/ger 